\title{
The needs of sustainability: the problem of data availability for calculating indicators
}

\author{
F. M. Pulselli, S. Bastianoni, V. Niccolucci \& E. Tiezzi \\ Department of Chemical and Biosystems Sciences, University of Siena, \\ Siena, Italy
}

\begin{abstract}
New instruments and scientific tools are necessary to improve our knowledge about the state and the possible evolution of complex systems, both natural and anthropic, from a sustainability viewpoint. In order to achieve the assessment of environmental sustainability, several holistic methods have been developed in the last two decades that are often applied worldwide. If holistic methodologies are to be implemented for the study of anthropic systems, such as territorial systems or production processes, in order to calculate synthetic sustainability indicators, then the availability of the most reliable and consistent data set is a condicio sine qua non to obtain a verisimilar representation of reality. Nowadays, databases created and usually provided by institutions seem to neglect important aspects of the relationship between human life and the biophysical bases which it is founded on. In other words, while it is relatively easy to obtain information about economic aspects of human activity (in monetary terms), it is arduous to appreciate the physical essence of flows and stocks of natural resources directly and indirectly involved in the same processes. This paper shows the application and comparison of more than thirty indicators applied to territorial systems, in order to highlight their complementarities and overlapping and the most relevant data to be collected.
\end{abstract}

\section{Introduction}

Today, the progressive spreading of the concept of sustainable development is leading people to look for solutions from a political, economic, social, institutional and environmental point of view. This new tendency, that may be defined as "therapeutic" (with respect to various problems that have arisen in 
recent years), is often partial and only effective in the short run, contravening the basic element of sustainability: time. In our opinion, before any "sustainability therapy", it is necessary to implement a "sustainability diagnosis" on the basis of an objective analysis of the environmental platform which human activities are based upon. Currently, the lack of diagnostic instruments is often mentioned by different documents. Article 40 of the Agenda 21 (UNCED, [10]) deals widely with sustainability indicators: "Indicators of sustainable development need to be developed to provide solid bases for decision-making at all levels and to contribute to a self-regulating sustainability of integrated environment and development systems". From this statement, it is clear that a serious diagnostic analysis is a necessary and preliminary condition for designing consistent sustainable policies. Measuring sustainability is an ambitious task, that is different from assessing how clean or polluted a given system is, and implies several levels of knowledge of the system under study. For this reason, advances in scientific research play a key role in supporting decision making. The territorial context is conceived as a complex, dynamic and open system in which several components develop and interact with each other. The choice of methods and indicators as instruments for assessing sustainability is a key point of such an analysis. The holistic vision, that considers the world as an integrated ensemble rather than a set of parts separated from each other, seems to be the most appropriate approach to adopt for the study and analysis of anthropic systems.

\section{Methods}

Sustainability is a state of the ecosystem that consists of interrelated components such as biotic elements and economic systems, in which the structure and the functions of each component should be maintained for a long period of time. A sustainability assessment can be performed on the basis of the flows of energy and matter and deviations can be corrected by means of socio-economic measures (Ruth, [6]). Some methods are presented in order to evaluate different aspects of the impacts of human activity and assess the territorial sustainability: Emergy evaluation, Ecological Footprint analysis, Greenhouse gas inventory and Remote sensing analysis. They are chosen in order to represent, under different viewpoints, the behaviour of a population that is in connection with the environment. The joint use of different methods gives rise to a holistic view of the system in order to implement suitable policies at different levels: territorial planning, resource and energy management, land use, etc. For each cited indicator the correspondent symbol (then used in Figure 1) is reported between brackets.

\subsection{Emergy evaluation}

To take into account all the flows of resources (natural and manufactured) supporting a system (national, regional or productive) and to evaluate the environmental work necessary in order to make them available, the concept of Emergy was introduced by Howard Odum [4,5]. He defined emergy as the quantity of solar energy necessary (directly or indirectly) to obtain a product or 
an energy flow in a given process. Emergy is the memory of all the solar energy that has been necessary to feed a given process. Hence, emergy is the common basis which a system of environmental accounting can be built on. Its unit is the solar emergy Joule (sej). In order to convert all the inputs supporting a system into sej, the concept of Transformity is introduced. Solar Transformity is defined as the emergy required per unit of product or service (Ulgiati et al. [8]) or as the solar energy directly or indirectly necessary to obtain one unit of energy or mass (Joule or gram) of another type of energy.

Once all the inputs are classified in renewable $(\mathrm{R})$ and non-renewable $(\mathrm{N})$ resources and local (L) and imported (F) inputs, some synthetic indicators of the environmental performance can be calculated. For example, the Environmental Loading Ratio (ELR) is the ratio of non-renewable (local and imported) emergy to renewable environmental emergy; the Emergy per Person (EpP) is the ratio of total emergy to the inhabitants of the system; the Empower Density (EmD) is the ratio of total emergy to the area (expressed in sej per $\mathrm{m}^{2}$ ); EYR is the ratio of the total emergy flow $(\mathrm{Em})$ to the imported inputs $(\mathrm{F})$.

\subsection{Ecological Footprint}

The Ecological Footprint (EF), introduced by W. Rees and M. Wackernagel [9], is defined as the total area of ecologically productive land (forests, arable land, pasture, built-up area, etc.) and water ecosystem required to produce the resources and services consumed by a given population, as well as to assimilate wastes generated by that population. The ecological footprint formulation starts from the consumption of goods and services by the population, and is based on the hypothesis that every unit of energy and matter derives, directly or indirectly, from a certain extension of land. The conversion of all consumed inputs into equivalent hectares of land necessary to produce the resources and to absorb the emissions is possible by means of suitable conversion factors provided on the basis of the global average productivity of land. The analysis also defines a bioproductive capacity of a certain region (local, national or global), and comparisons between the $\mathrm{EF}$ and the biocapacity (BC) of an area determine the so-called ecological deficit or surplus. The ecological deficit provides an evaluation of the local overload, revealing how much a region depends on extraterritorial productive capacity.

\subsection{Greenhouse gas inventory}

The anthropic emissions of greenhouse gases have global implications in terms of sustainability. According to the IPCC guidelines [3], the emissions in the energy sector, agriculture, land-use change and forestry and waste are monitored. The main result is the comparison between the emission of equivalent $\mathrm{CO}_{2}(\mathrm{Eq}$ $\mathrm{CO}_{2}$ ) and the absorption capacity of the ecosystems inside the territory (Abs $\mathrm{CO}_{2}$ ): their difference gives the net $\mathrm{CO}_{2}$. The inventory includes emissions of $\mathrm{CO}_{2}, \mathrm{CH}_{4}, \mathrm{~N}_{2} \mathrm{O}, \mathrm{NO}_{\mathrm{x}}, \mathrm{CO}$, NMVOC (non-methane volatile organic compounds), $\mathrm{SO}_{2}, \mathrm{HFC}, \mathrm{PFC}, \mathrm{SF}_{6}$ and the absorption of $\mathrm{CO}_{2}$. It is consistent with the policy of emission reduction and is a useful way of assigning their responsibility among different sectors and areas. 


\subsection{Remote sensing analysis}

Remote sensing means that instruments or recorders are not in direct contact with the objects under investigation, and observations and measurements of those objects occur from a distance. This method (Focardi et al., [2]) is implemented by using satellite images, and focuses on the measurement of energy at different wavelengths that is emitted, transmitted or reflected from an object in order to determine certain properties of it. The results of the analysis enable one to gain information on the spatial characteristics of a territory by combining a series of multitemporal and multispectral images, and to determine, for example, land cover (ESI), biomass cover (NDVI) and emission characteristics (RTI).

Table 1: Data necessary for the Emergy Evaluation of a territorial system (data expressed in unit per year).

\begin{tabular}{|c|c|c|c|}
\hline Input & Unit & Input & Unit \\
\hline \multicolumn{2}{|l|}{ Local Renewable Emergy (R) } & \multicolumn{2}{|l|}{ Imported Goods and Services (F2) } \\
\hline Sunlight & $\mathrm{J}$ & \multicolumn{2}{|l|}{ Breeding, Hunting And Fishing } \\
\hline Rain & $\mathrm{g}$ & Products of breeding & $\mathrm{g}$ or $\mathrm{J}$ \\
\hline Wind & $\mathrm{J}$ & Products of forestry & $\mathrm{g}$ or $\mathrm{J}$ \\
\hline Geothermal heat & $\mathrm{J}$ & Products of fishing and hunting & g or $\mathrm{J}$ \\
\hline Rivers & $\mathrm{g}$ & & \\
\hline Tidal energy & $\mathrm{J}$ & \multicolumn{2}{|l|}{ Imported Goods and Services (F2) } \\
\hline \multirow[t]{2}{*}{ Seawater } & $\mathrm{g}$ & Minerals & \\
\hline & & Metallic minerals & $\mathrm{g}$ \\
\hline \multicolumn{2}{|c|}{ Local Non-Renewable Emergy (N) } & Non metallic minerals & $\mathrm{g}$ \\
\hline Soil erosion & $\mathrm{J}$ & & \\
\hline Water consumption & $\mathrm{g}$ & \multicolumn{2}{|c|}{ Imported Goods and Services (F2) } \\
\hline \multirow[t]{2}{*}{ Extracted minerals } & $\mathrm{g}$ & Manufacturing And Craft & \\
\hline & & Food industry & $\mathrm{g}$ or $\mathrm{J}$ \\
\hline \multicolumn{2}{|l|}{ Imported Energy Sources (F1) } & Tobacco industry & $\mathrm{g}$ \\
\hline Electricity & $\mathrm{J}$ & Leather industry & $\mathrm{J}$ \\
\hline Gasoline and diesel & $\mathrm{J}$ & Textile industry & $\mathrm{J}$ \\
\hline Fuel oil, LPG, lubrificants & $\mathrm{J}$ & Furniture and fixtures industry & $\mathrm{J}$ \\
\hline \multirow[t]{2}{*}{ Natural gas } & $\mathrm{J}$ & Wood industry & $\mathrm{g}$ or $\mathrm{J}$ \\
\hline & & Paper industry & $\mathrm{g}$ or $\mathrm{J}$ \\
\hline \multicolumn{2}{|l|}{$* * *$} & Industry of graphics & $\mathrm{g}$ or $\mathrm{J}$ \\
\hline & & Metallurgical industry & $\mathrm{g}$ \\
\hline \multicolumn{2}{|c|}{ Imported Goods and Services (F2) } & Mechanic industry & $\mathrm{g}$ \\
\hline \multicolumn{2}{|c|}{ Agriculture } & Industry of minerals & $\mathrm{g}$ \\
\hline Crops and legumes & $\mathrm{J}$ & Chemical industry & $\mathrm{g}$ \\
\hline $\begin{array}{l}\text { Fruits, seeds, spices and } \\
\text { tobacco }\end{array}$ & $\mathrm{J}$ & Industry of rubber & $\mathrm{g}$ \\
\hline Plants and flowers & $\mathrm{g}$ & Other industries & $\mathrm{g}$ \\
\hline
\end{tabular}

\section{The needs for a sustainability "diagnosis"}

a) the availability of the most reliable and coherent data is a condicio sine qua non to obtain a verisimilar representation of reality and apply methods Synthetic indicators usually result from a translation of different elements and phenomena into a common unit. The procedure starts by identifying those elements relevant for the analysis and collecting raw data about them. The tables (1,2 and 3) summarize the detailed raw information that would be necessary to implement the methods described above. 
It is clear that the reliability of a method is proportional to the availability of data. Without a systematic recognition of statistical information and measurement of local realities, no verisimilar picture of the state of the system or prediction for the future is possible. Territorial planning activity is difficult if a Public Administration does not know what is happening within its territory. Usually, socio-economic information is the easiest to find, whereas environmental aspects are often neglected.

Table 2: Data necessary for the Ecological Footprint analysis of a territorial system (emissions, wastes, tourists, consumption and production are expressed in unit per year).

\begin{tabular}{|c|c|c|c|}
\hline Input & Unit & Input & Unit \\
\hline \multicolumn{2}{|l|}{ General Data } & Chemical Products & $\mathrm{t}$ \\
\hline Area & $\mathrm{m}^{2}$ & Metallic Products & $\mathrm{t}$ \\
\hline Population & n. of inh. & Non metallic Products & $\mathrm{t}$ \\
\hline $\begin{array}{l}\text { Land use: cropland, built-up, } \\
\text { grazing, forest, marine lands }\end{array}$ & $\mathrm{m}^{2}$ & & \\
\hline $\begin{array}{l}\text { Emiss. of pollutants: } \mathrm{CO}_{2}, \mathrm{CH}_{4} \text {, } \\
\text { other gas., liq. and solid poll. }\end{array}$ & tor $\mathrm{m}^{3}$ & Productions & \\
\hline Prod. and recycling of wastes & $\mathrm{t}$ & Agricultural products & \\
\hline \multirow[t]{2}{*}{ Tourists } & n. & Products of Cultivation & $\mathrm{t}$ \\
\hline & & Derivative of products & $\mathrm{t}$ \\
\hline \multicolumn{4}{|l|}{ Consumption } \\
\hline Products of animal origin & & Zootechny & \\
\hline Food & $\mathrm{t}$ & Number of heads & $\mathrm{n}$. \\
\hline Other products & $\mathrm{t}$ & Derivatives (food or other goods) & $\mathrm{t}$ \\
\hline \multicolumn{4}{|l|}{ Products of vegetal origin } \\
\hline Food & $\mathrm{t}$ & Energy & \\
\hline \multirow[t]{2}{*}{ Other products } & $\mathrm{t}$ & Production of electricity & GWh \\
\hline & & Autoproduction of electricity & GWh \\
\hline Energy & & Incineration of wastes & GWh \\
\hline Coal & $\mathrm{t}$ & & \\
\hline Fossil fuels & $\mathrm{t}$ & Chemical Products & $\mathrm{t}$ \\
\hline Methane & $\mathrm{m}^{3}$ & Metallic Products & $\mathrm{t}$ \\
\hline Electricity & GWh & Non metallic Products & $\mathrm{t}$ \\
\hline
\end{tabular}

For example, the number of employees in a given sector is well known and long time series are registered, while the extracted quantity of sand $\left(\right.$ in $\mathrm{m}^{3}$, not in monetary terms!) or the urban or industrial consumption of water is not so accessible. Currently, there is a growing tendency towards the collection of data in economic terms, or relevant for economic purposes, rather then information on the biophysical basis which every economic, social or urban system is founded on. In general, before any investigation into the sustainability of a territorial system, institutions should verify if they are prepared to plan suitable investments in information and knowledge.

b) sustainability indicators must be calculated by computing raw data in order to obtain synthetic information on wide complex phenomena

Depending on the availability of data, it is possible to describe various phenomena. As it has been shown, all the items are expressed in different units that must be converted and integrated together in order to calculate one or more synthetic indicators representative of a more complex picture. Indicators are thus 
the results of mathematical combinations of elements and conversion factors, and the purpose of such a calculation is to highlight the most important mechanisms characterizing the territorial system, most of them stimulated by human activity. The physical-based methods described above imply that all the information is converted into a common unit (sej for emergy evaluation, global equivalent hectare for ecological footprint, equivalent $\mathrm{CO}_{2}$ for Greenhouse gas inventory) on the basis of objective and not arbitrary conversions. This avoids the use of incommensurable indicators, that make it difficult to rank systems when they are compared with each other, as in the case of some multicriteria analyses. We have used a series of indicators that can be used within a sustainability analysis. In particular, we present some selected data together with most of the indicators from the methods presented above. They contain information that is often easily understandable by policy makers, and that can steer planning and programming policies as well as give information on the current and optimal level of urbanization, industrial development, energy and resource management, etc.

Table 3: Data necessary for the Greenhouse Gas Inventory of a territorial system (production, consumption, rice and forest growth, combustion and wastes are expressed in unit per year).

\begin{tabular}{|c|c|c|c|}
\hline Input & Unit & Input & Unit \\
\hline Agriculture & & Energy Sector & \\
\hline Zootechny & n. of heads & LPG & $\mathrm{t}$ or $\mathrm{m}^{3}$ \\
\hline Rice growing & $\mathrm{t}$ & Natural Gas & $\mathrm{m}^{3}$ \\
\hline Combustion of residual & $\mathrm{t}$ & Wind & $\mathrm{t}$ or $\mathrm{m}^{3}$ \\
\hline Fertilizer & $\mathrm{t}$ or 1 & $\begin{array}{l}\text { Gasoline } \\
\text { Kerosene }\end{array}$ & $\begin{array}{l}t \text { or } m^{3} \\
t \text { or } m^{3}\end{array}$ \\
\hline Wastes & & Fuel oil & tor $\mathrm{m}^{3}$ \\
\hline Solid wastes production & $\mathrm{t}$ & Electricity & GWh \\
\hline Commodity composition & - & & \\
\hline Sewage & $\mathrm{m}^{3}$ or 1 & & \\
\hline & & \multirow{2}{*}{\multicolumn{2}{|c|}{$\begin{array}{l}\text { Forestal Sector } \\
\left.\text { - Wooded areas (ha) and growth ( } \mathrm{m}^{3} / \mathrm{ha}\right) \text { of: } \\
\text { Chesnut }\end{array}$}} \\
\hline Industrial Sector (productions) & & & \\
\hline Concrete & $\mathrm{t}$ & Beech & \\
\hline Mass concrete & $\mathrm{t}$ & Hop-hornbeam & \\
\hline Limestone & $\mathrm{t}$ & Downy Oak & \\
\hline Sodium Carbonate & $\mathrm{t}$ & Turkey Oak & \\
\hline Asphalt & $\mathrm{t}$ & Holm-Oak & \\
\hline Glass & $\mathrm{t}$ & Silver fir & \\
\hline Ammonia & $\mathrm{t}$ & Stone pine & \\
\hline Nitric acid & $\mathrm{t}$ & Austrian pine & \\
\hline Iron & $\mathrm{t}$ & Robinia & \\
\hline Steel & $\mathrm{t}$ & Cypress & \\
\hline Aluminium & $\mathrm{t}$ & - Wood Use & \\
\hline Paper & $\mathrm{t}$ & Working timber & $\mathrm{m}^{3}$ or $\mathrm{kg}$ \\
\hline Liquors & 1 & Firewood & $\mathrm{m}^{3}$ or $\mathrm{kg}$ \\
\hline Food & $\mathrm{t}$ & - Blazes: burnt-out areas & ha \\
\hline
\end{tabular}

c) the integration of methods and indicators is possible through statistical instruments, in order to efficiently provide the most reliable and usable information - A case study.

A research project, called "Spin-Eco" (The SPIn-Eco Project (the acronym means "Sustainability of the Province [of Siena] by means of Ecodynamic 
Indicators", that explains the need to relate ecosystems to thermodynamics, ecology and the social sciences in order to arrive at satisfactory solutions for sustainable development and environmental management) is a multi-year (20012004) research program proposed by the Provincial Administration of Siena and funded by the Monte dei Paschi Foundation.), has been developed by a team led by the University of Siena, Italy, with the purpose of assessing the environmental conditions and the sustainability of the Province of Siena by means of indicators. Different methods and all the indicators presented have been calculated for the whole territory of the Province and the 36 Municipalities that compose it. Finally, the results of the project (the results of this project will be published within a Special Issue of the Journal of Environmental Management in the course of 2006) consist in a series of indicators (26) calculated for a series of comparable territorial systems (36).

In this context, the Principal Component Analysis (PCA) has been applied in order to analyse relationships, as well as possible overlapping and complementarities among indicators. PCA is a mathematical transformation in which linear combinations of the input variables (here indicators) are created; the new variables, called principal components (PCs), explain as much of the variation as possible of the original data.

PCA has a twofold function: 1) it provides a way of reducing the dimensionality of the data; 2 ) it is a powerful visualization tool that enables graphic representation of intersample and intervariable relationships for exploratory data analysis. In other words, it plays both a methodological role, as a statistical computation method, and a practical one, presenting an overview of the contribution of each indicator in terms of information. However, this does not mean that PCA is a further instrument of synthesis, because combining information is often tantamount to a loss of information. Notwithstanding, it can be convenient in order to optimize, even from an economic point of view, the combination of indicators necessary to know some aspects of an anthropic system because "a large number of original variables are reduced to a small number of transformed variables" (Saisana and Tarantola, [7], p. 12).

The results of the PCA within the SPIn-Eco Project (see Bastianoni et al., [1]) can be summarized in the following figures that show the Principal Component Loading Plot and a Principal Component Biplot. They represent the first two PCs with a cumulative explanation of 55.9\%. Figure 1 shows the eigenvectors for the indicators used within SPIn-Eco Project and Figure 2 shows the plot of the 36 municipalities according to their similarity, utilizing combined information of the applied indicators. The characteristics of different sites can be highlighted by their position: according to the $\mathrm{PC} 1$, on the left side (high value of $\mathrm{P}, \mathrm{PD}, \mathrm{I}, \mathrm{CO}_{2}$ and F) we can find the largest urban areas, for example the city of Siena (32), whereas the municipalities on the left side (high value of BC, ITS, NDVI and $\mathrm{CO}_{2}$ absorbed) are characterized by agriculture, forests and low population density (Monticiano, 18; Radicondoli, 25). PC2 isolated three sites with high value of N, EYR, ELR, EpP, Em and EmD, because of the exploitation of local non-renewable environmental resources, namely yellow marble (Sovicille, 34), clay (Trequanda, 36) and travertine (Rapolano, 26). 


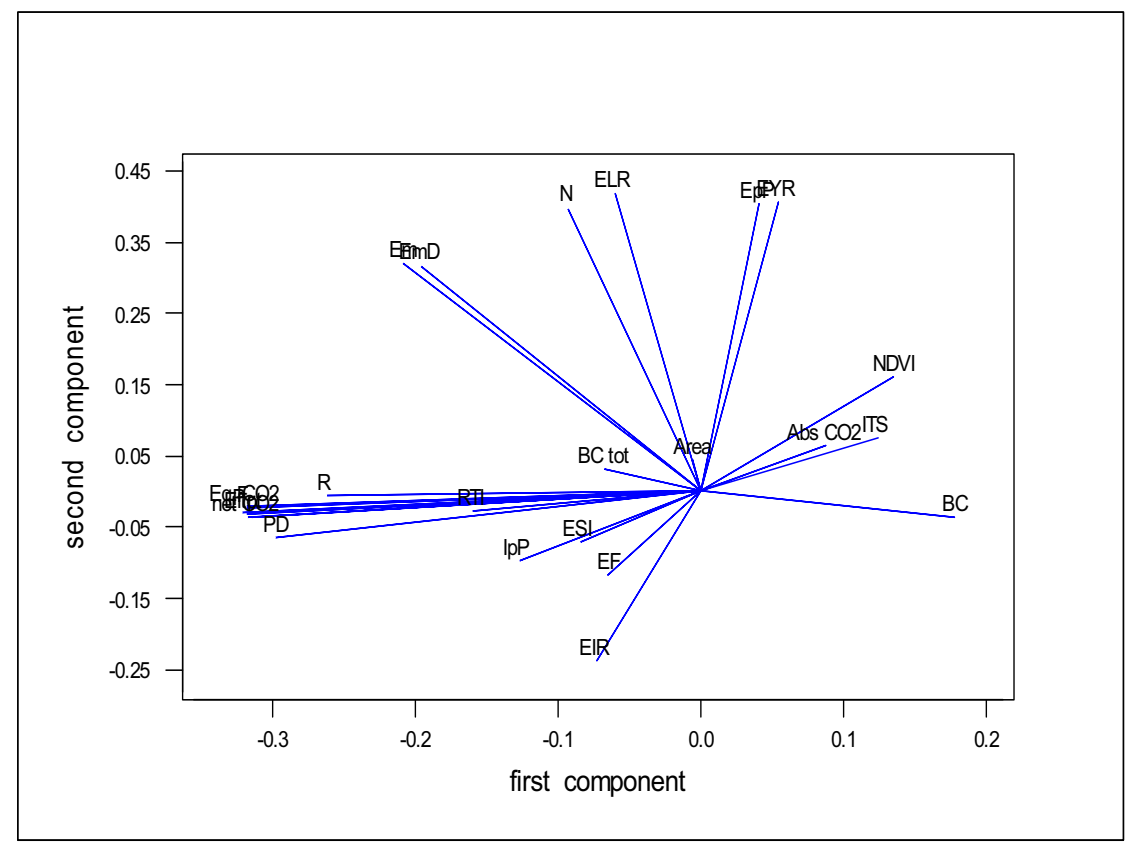

Figure 1: Principal Components Loading Plot. On the left side, where several lines and symbols overlap, we can find: Population (P), Population Density (PD), Total Income (I), Local Renewable Resources (R), Purchased non-local Resources (F), Equivalent $\mathrm{CO}_{2}$, Net $\mathrm{CO}_{2}$, Total Ecological Footprint (EFtot) (source: Bastianoni et al., [1]).

This analysis can be a reference point for planning (or orienting) human activities within a territory, since some new elements emerge such as homogeneity and diversity. In particular, the application of these results to the network of subsystems managed by the Province of Siena have shown that a certain degree of diversity among the sites is due to different environmental conditions or to different economic/urban/industrial characteristics. These diversities need to be preserved in order to reduce the fragility of the whole system with respect, for example, to possible economic crises in one particular sector.

From a methodological point of view, correlations and anti-correlations among indicators can be represented, on the basis of the position of the lines in the figures: at least for what concerns the first two PCs, the closer the direction of the lines, the more the indicators are correlated within this data set; a $90^{\circ}$ angle means total independency, a $180^{\circ}$ angle anti-correlation. High level of correlation exists among $\mathrm{CO}_{2 \mathrm{eq}}$ emissions, EFtot, $\mathrm{F}$ and I, typical expressions of the presence of humans (P). At the same time, the low level of correlation between $\mathrm{EF}$ and EpP is quite surprising, since the methods of Emergy and Ecological Footprint seem similar. Actually, they calculate the environmental cost of human consumption, the former measuring it through the direct and indirect solar energy requirement, the latter through the amount of land needed. 
However, the low level of correlation is explained by the fact that, while emergy evaluation computes the non-renewable materials extracted locally $(\mathrm{N})$, EF does not consider these types of materials, preferring to use renewable substitutes when possible. Furthermore, while Emergy takes into account the total consumptions of goods within the area, Ecological Footprint includes only the household consumptions, without considering industrial consumptions and similar.

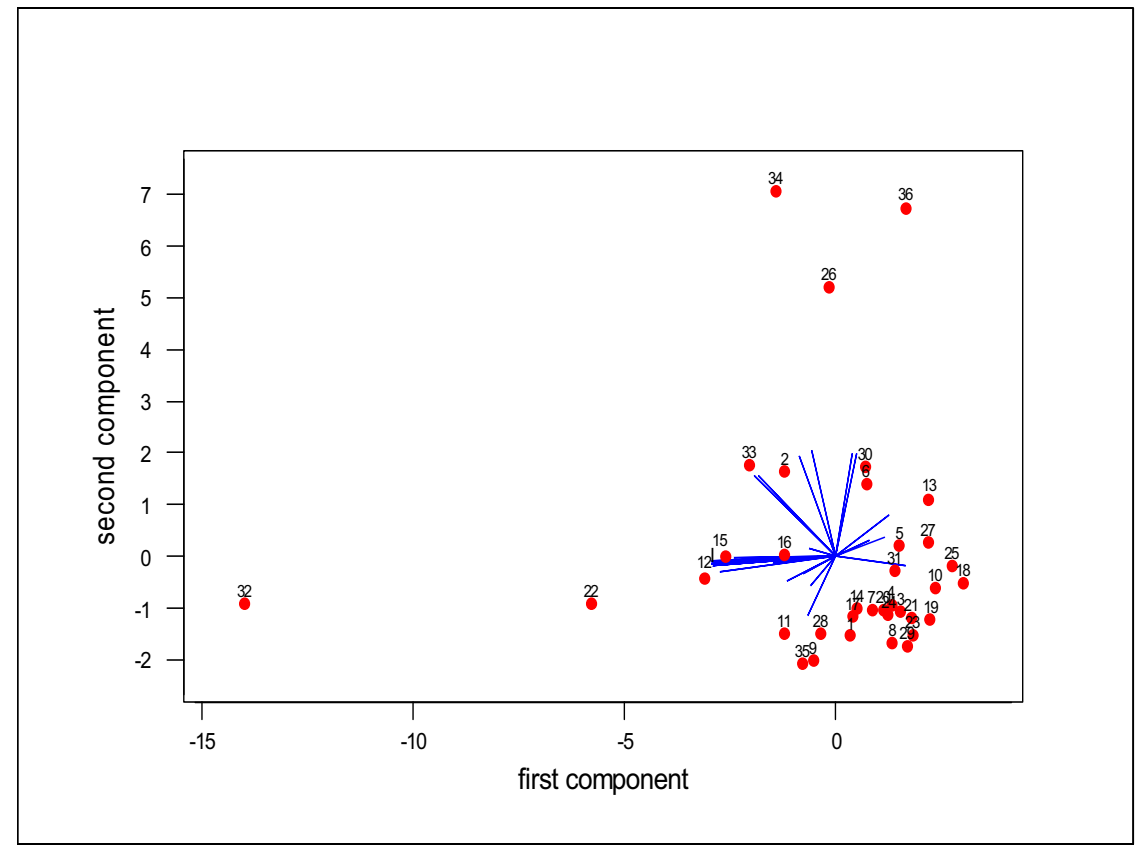

Figure 2: Principal Components Biplot. The numbers represent the Municipalities of the Province of Siena according to the following alphabetical order: 1 Abbadia S. Salvatore; 2 Asciano; 3 Buonconvento; 4 Casole; 5 Castellina in Chianti; 6 Castelnuovo Berardenga; 7 Castiglione d'Orcia; 8 Cetona; 9 Chianciano; 10 Chiusdino; 11 Chiusi; 12 Colle Val d'Elsa; 13 Gaiole in Chianti; 14 Montalcino; 15 Montepulciano; 16 Monteriggioni; 17 Monteroni; 18 Monticiano; 19 Murlo; 20 Piancastagnaio; 21 Pienza; 22 Poggibonsi; 23 Radda in Chianti; 24 Radicofani; 25 Radicondoli; 26 Rapolano; 27 San Casciano dei Bagni; 28 San Gimignano; 29 San Giovanni d'Asso; 30 San Quirico d'Orcia; 31 Sarteano; 32 Siena; 33 Sinalunga; 34 Sovicille; 35 Torrita; 36 Trequanda (source: Bastianoni et al., [1]).

The application of the PCA to a relevant number of results enabled this project to understand the degree of congruence of the indicators and the possibility of recognizing patterns or clusters in the description of the subsystems that compose the Province of Siena. 


\section{Conclusion}

The use of synthetic indicators is a fundamental step within a sustainability assessment. They are the results of the application of suitable methods useful for the analysis of some aspects of the complex relationship between human behaviour and the environment. A reliable and available set of data must be collected and then computed according to rigorous procedures, preferably based on physical measures that are objective and not arbitrary. Further statistical computation (for instance PCA) may be of help in order to select the best ensemble of indicators to calculate. Statistical information plays an important role in articulating a research project whose purpose is to assess the sustainability of one or more systems. For this reason, public administrations should be requested to invest more resources in acquiring information on the state of the system as well as in scientific means in order to understand the sense of their policies from the point of view of sustainability.

\section{References}

[1] Bastianoni, S., Gramatica, P., Pulselli, F.M., Focardi, S., Tiezzi, E.B.P., 2006. Correlations and complementarities in data and methods through Principal Components Analysis (PCA) applied to the results of the SPInEco project. Journal of Environmental Management, in press.

[2] Focardi, S., Loiselle, S., Mazzuoli, S., Bracchini, L., Dattilo, A.M., Rossi, C., 2006. Satellite based indices in the analysis of land cover for municipalities in the Province of Siena. Journal of Environmental Management, in press.

[3] IPCC, 1996. Greenhouse Gas Inventory. Reporting Instructions, 1996 (revised). IPCC, Intergovernmental Panel on Climate Change, 1,2,3.

[4] Odum, H.T., 1988. Self organisation, transformity and information. Science, 242, 1132-1139.

[5] Odum, H.T., 1996. Environmental Accounting. Emergy and Environmental Decision Making. John Wiley and Sons, New York.

[6] Ruth, M., 1993. Integrating economics, ecology and thermodynamics. Kluwer Academic Publishers, Dordrecht, Netherlands, $251 \mathrm{pp}$.

[7] Saisana, M. and Tarantola, S., 2002. State-of-the-art report on current methodologies and practices for composite indicator development. Report EUR 20408 EN. European Commission-Joint Research Centre, Ispra.

[8] Ulgiati, S., Odum, H.T. and Bastianoni, S., 1994. Emergy use, environmental loading and sustainability. An emergy analysis of Italy. Ecological Modelling, 73, 215-268.

[9] Wackernagel, M., Rees, W., 1996. The Ecological Footprint: reducing human impact on the Earth, New Society, Gabriola Island, BC, Canada.

[10] UNCED, 1992. Agenda 21, Chapter 40, Information for decision making. Rio de Janeiro 3rd-14th June, 1992. 